\title{
Projetos de Vida de Adultos Jovens Portadores de HIV por Transmissão Vertical: estudo exploratório com usuários de um ambulatório de Infectologia'
}

\section{Life Projects of Young Adults with HIV acquired by Vertical Transmission: an exploratory study with patients of an infectious diseases' outpatients department}

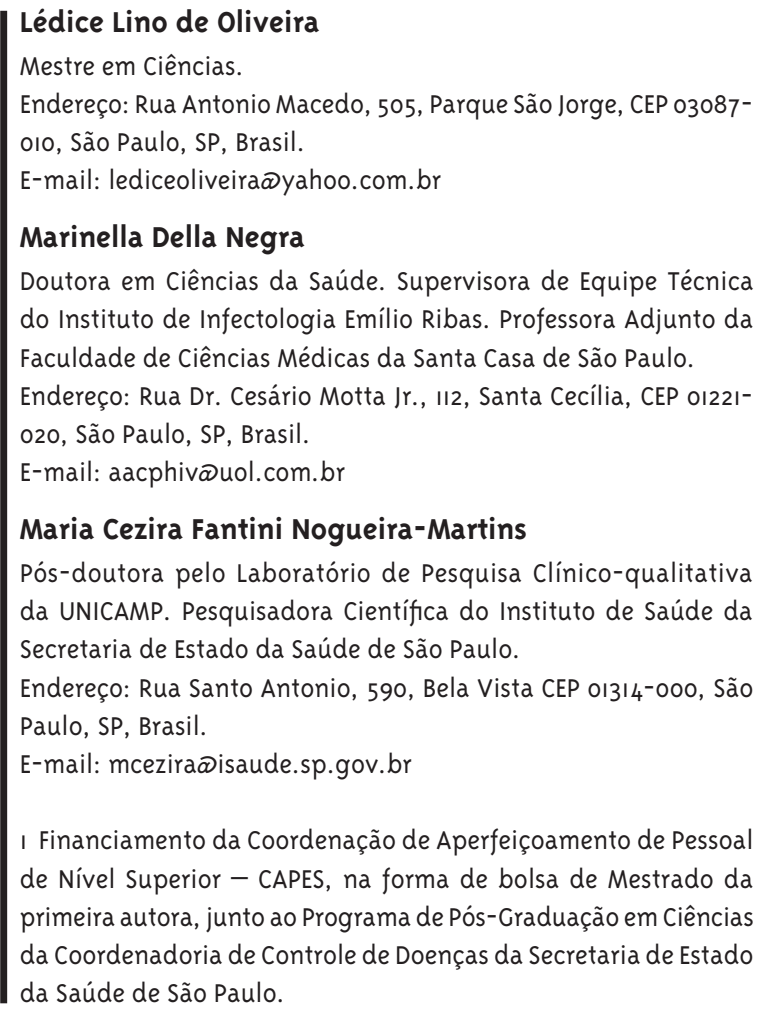

\section{Maria Cezira Fantini Nogueira-Martins}

Pós-doutora pelo Laboratório de Pesquisa Clínico-qualitativa da UNICAMP. Pesquisadora Científica do Instituto de Saúde da Secretaria de Estado da Saúde de São Paulo.

Endereço: Rua Santo Antonio, 590, Bela Vista CEP 01314-000, São Paulo, SP, Brasil.

E-mail: mceziraळisaude.sp.gov.br

I Financiamento da Coordenação de Aperfeiçoamento de Pessoal de Nível Superior - CAPES, na forma de bolsa de Mestrado da primeira autora, junto ao Programa de Pós-Graduação em Ciências da Coordenadoria de Controle de Doenças da Secretaria de Estado da Saúde de São Paulo.

\section{Resumo}

Esta pesquisa teve o intuito de conhecer os projetos de vida de jovens adultos que convivem com o HIV/ aids a partir da transmissão vertical, com relação a: estudo, trabalho e constituição familiar. Outro objetivo foi o de conhecer sua vivência no que diz respeito à assistência recebida. Como instrumentos, foram utilizados: questionário sociodemográfico e entrevista semiestruturada. Foram realizadas 16 entrevistas com jovens de idade entre 18 e 22 anos, usuários de um ambulatório de um hospital público especializado na área de Infectologia. 0 material obtido nas entrevistas foi analisado segundo os princípios da análise temática. Foram encontradas seis categorias temáticas: estudo e escolaridade; trabalho e emprego; sexualidade e constituição familiar; vivência de preconceito; adesão ao tratamento; acolhimento. Os entrevistados referiram que a escola é importante meio para a inserção social e para a conquista da autonomia. O trabalho foi apresentado como principal fonte de subsistência e de independência. 0 exercício da sexualidade foi marcado pela situação de existência do HIV, determinando cuidados especiais; quanto à conjugalidade, os projetos dos entrevistados são variados: união informal, casamento oficial, vida sem cônjuge. No que diz respeito à maternidade/paternidade, os projetos são marcadamente influenciados pela portabilidade do HIV, despertando dúvidas e receios. Os entrevistados relataram a existência do preconceito em vários contextos. Quanto à adesão ao tratamen- 
to, revelaram a existência tanto de dificuldades como de mecanismos criados para enfrentá-las. 0 acolhimento por parte de familiares, amigos e profissionais da saúde foi considerado fundamental para o desenvolvimento e a manutenção de seus projetos de vida.

Palavras-chave: Adulto jovem; HIV; Ambulatório hospitalar; Humanização da assistência.

\section{Abstract}

This research had the intention to understand the life projects of young adults living with HIV/Aids infected through vertical transmission: how they deal with studies, work and with building a family. Another objective was to know their experiences regarding health assistance received. The research method was: socio-demographic questionnaires and semi-structured interviews. Sixteen interviews were performed with people between eighteen and twenty two years-old who were users of a public out patients service specialized in Infectious Diseases. Data from the interviews was analyzed according to the principles of thematic analysis. Six thematic categories were found: study and schooling; labor and employment; sexuality and family building; experiences of prejudice; adherence to treatment and reception at the health service.I Interviewees appointed the whole education ambient as an important way to reach social inclusion, as well as autonomy. They presented their working life as the first source of subsistence and independence. The exercise of their sexuality was marked by HIV, implicating in special care. Regarding conjugality, the interviewees' projects were varied: informal union, legal marriage and life without partner. The projects involving maternity/paternity were strongly influenced by the presence of HIV, which results in many doubts and worries. Interviewees reported the existence of prejudice in various situations. As regarding the adherence to treatment, subjects talked about difficulties and coping mechanisms. Being well received by friends, coworkers and family was considered pivotal to developing and maintaining life projects.

Keywords: Young Adult; HIV; Outpatient Clinics; Humanization of Assistance. 


\section{Introdução}

A construção do projeto de vida é contínua na existência do indivíduo. Entretanto, segundo Boutinet (1990), entre o grupo de adultos jovens essa construção apresenta intensidade mais marcante do que em outras fases, já que a passagem para a vida adulta geralmente apresenta um caráter desafiador, em função da necessidade de aquisição de autonomia e de inserção em uma atividade produtiva.

Para Gutierrez e Minayo (2008), a família, a escola e o trabalho se interconectam em um todo integrado e merecem ser tomados em conta e explorados nos estudos psicossociais, pois são pilares que mantêm a estrutura da identidade do sujeito, tendo assim, interferência direta em seu projeto de vida.

Quanto à família, é importante ressaltar que ela é mediadora entre o indivíduo e a sociedade; é por meio da família que o indivíduo aprende a perceber o mundo e a se situar nele (Reis, 2001). É uma instituição criada por meio das relações entre os seres humanos, e se constitui de diferentes formas para responder às necessidades sociais. 0 grupo familiar exerce também uma função ideológica, pois ensina a seus membros como se comportar fora das relações familiares sendo, pois, formadora do cidadão de acordo com a sociedade na qual está inserida (Reis, 2001). No que diz respeito às configurações familiares, é importante ressaltar que novos e importantes elementos têm surgido no panorama social contemporâneo. Diante das transformações ocorridas nas sociedades e nas situações de vida diversificadas e em constante mudança, as escolhas e opções dos homens e mulheres em relação à vida afetivo-sexual passam a ser flexíveis e plurais, assim como o casamento e a noção de família (Amazonas e Braga, 2006).

No que tange à escola, segundo Sarriera e colaboradores (2004), esta exerce um papel determinante na vida do jovem, visto que, por meio das dificuldades que provoca ou pelas contribuições que oferece, estimula a sua inserção na sociedade e no mundo do trabalho. Segundo Davis e colaboradores (1989), a escola deve ir além da construção de conhecimentos, propiciando situações em que os alunos possam participar ativamente e interagir. Para Vygotsky (2007), a possibilidade de se apropriar das conquistas ante- riores, assim como de se constituir enquanto sujeito, está, por um lado, condicionada ao desenvolvimento do sistema nervoso e, por outro, à qualidade das trocas que são dadas entre os indivíduos, ou seja, à qualidade do processo educativo do qual fazem parte. Freire (1987) salienta que a educação não pode servir como simples depositária de conteúdo; deve ser problematizadora do homem em suas relações com o mundo. Segundo este autor, a educação não pode se fundar em uma compreensão dos homens como seres "vazios", a quem o mundo "enche" de conteúdos; a educação deve, assim, estar a serviço da libertação do indivíduo.

Quanto ao trabalho, é um dos elementos capazes de conferir identidade ao sujeito. Para Ciampa (1999), "é pelo agir, pelo fazer, que alguém se torna algo: ao pecar, pecador; ao desobedecer, desobediente; ao trabalhar, trabalhador" (p. 64); o autor apresenta, assim, o significado subjetivo do trabalho, indo além da conotação de subsistência. Conforme Sarriera e colaboradores (2004), o jovem precisa construir sua identidade sobre bases sólidas, a fim de que o processo de autonomia e de inserção social seja exitoso. Tal estruturação, segundo os autores, dá-se por meio de um processo de interação com diversos grupos dos quais o jovem participa, ora igualando-se, ora diferenciando-se, sendo que uma das categorias na constituição da identidade certamente é o trabalho, ou seja, o fato de ser trabalhador. Para Arendt (1987), o trabalho não é a essência do homem, mas, sim, resultado de um processo cultural que, por meio da ação, faz com que o homem interaja com seus semelhantes; portanto, a natureza do trabalho é eminentemente social.

É importante destacar que as perspectivas ligadas à tríade família, escola e trabalho são elementos importantes para a inserção/reinserção social de vários grupos com características especiais, na luta contra a exclusão social (Catão, 2001; Nascimento, 2002). Sawaia (1999) aponta que, para esses casos, os três elementos citados podem contribuir para que o jovem se distancie da marginalidade.

Os jovens adultos portadores de HIV, por terem, atualmente, a possibilidade de maior sobrevida, passam a vivenciar experiências semelhantes às dos jovens não portadores do vírus e se veem diante 
de questões como: continuidade do estudo; profissionalização; ingresso, permanência e ascensão no mercado de trabalho. Além disso, deparam-se também com as questões que dizem respeito às relações afetivas, à reprodução e à constituição familiar. Por outro lado, vivenciam diversas perdas sociais, que podem acarretar baixa autoestima, repressão da afetividade, medo da discriminação e a não procura por ajuda e tratamento (Guimarães e Raxach, 2002).

No que diz respeito ao trabalho, o indivíduo portador de HIV está amparado pela Constituição Federal contra qualquer atitude discriminatória com relação à sua sorologia e consequente perda do emprego, tendo garantido o direito a não declarar a sua condição sorológica em momento algum. $\mathrm{O}$ portador de HIV deve, no ambiente de trabalho, ter preservadas sua intimidade e sua dignidade. Ele poderá se negar a fazer o exame e/ou denunciar a empresa junto aos órgãos competentes, quando ela exigir a sorologia como critério para admissão (Organização Internacional do Trabalho, 2002). 0 portador de HIV pode receber o benefício da Lei Orgânica da Assistência Social (LOAS), que corresponde ao valor de um salário mínimo. Além desse benefício, poderá receber o auxílio doença enquanto estiver trabalhando e, temporariamente, vier a ter a capacidade limitada para a atividade; caso sua incapacidade venha a ser permanente, poderá receber a aposentadoria (OIT, 2002).

No âmbito da escola, especialmente quando os portadores do HIV ainda são crianças, a revelação do diagnóstico pode ser compartilhada com alguns de seus membros, desde que objetivando única e exclusivamente o benefício da saúde do aluno portador de HIV e de seu rendimento escolar. Segundo Cohen e colaboradores (1997), a decisão dos pais ou cuidadores de revelar o diagnóstico a alguns profissionais das escolas estava associada à possibilidade de melhor administração dos medicamentos e à facilitação do tratamento em instituições especializadas em HIV/aids, que exigia ausência em dias letivos.

Estudo com amostra adulta, soropositiva, revelou que a escolaridade mais elevada facilitaria o acesso à informação, propiciando maior habilidade para falar sobre a doença, obter apoio e fortalecer suas redes sociais. Pessoas com menor escolaridade necessitam de mais apoio social, estando mais vul- neráveis e mais dependentes (Seidl, 2001). Porém, as dificuldades quanto à escolaridade ainda são grandes com relação a essa população, especialmente no que tange à evasão escolar. Conforme aponta o Manual de Rotinas para assistência a adolescentes vivendo com HIV/aids (Brasil, 2006), a falta de motivação familiar, o medo da revelação do diagnóstico e a ocorrência de uma gravidez precoce são os três principais motivos para o abandono escolar entre os portadores de HIV.

A questão da conjugalidade tem sido colocada como um desafio também para os jovens com HIV/ aids. Por exemplo, no contexto da vida conjugal entre pessoas com sorologias diferentes para o HIV, os casais vivem a tensão relacionada ao risco sexual, oriunda da preocupação com uma possível contaminação do/a parceiro/a. A dimensão sexual-afetiva apresenta-se como questão central na vida desses jovens e, ainda que tenham dúvidas e preocupações, tais fatores não têm se mostrado impeditivos para o início da vida sexual e o planejamento de uma família (Ayres e col., 2004), preservando o desejo de permanecerem sexualmente ativos e realizarem suas escolhas reprodutivas (Polejack e Costa, 2002).

Por outro lado, o impacto no exercício da sexualidade do jovem portador de HIV pode se manifestar por meio da perda e/ou diminuição do desejo sexual, em decorrência de estados depressivos, baixa autoestima, efeitos adversos dos medicamentos, receio de reinfecções, dificuldades em manter/negociar o uso de preservativos e a recorrente lembrança da portabilidade do vírus HIV (Vernazza e col., 2006). Influenciados pelos estereótipos sociais, homens e mulheres podem ter sua sexualidade afetada pelo diagnóstico positivo para o HIV. A mulher, por vezes, passa a desqualificar seu corpo e sua maternidade; o homem pode passar por uma profunda crise de sua masculinidade. Assim, a sexualidade pode se tornar perigo, restrição e repressão, ao invés de exploração e prazer (Grimgerg, 2009).

Vários aspectos da tríade trabalho, estudo e constituição familiar, portanto, têm sido estudados com relação aos jovens que convivem com o HIV/aids. Conhecer essas dimensões no que diz respeito a um subgrupo específico, que é o daqueles que convivem com o HIV/aids a partir de transmissão vertical é a finalidade deste trabalho. 


\section{Objetivos}

Esta pesquisa teve o intuito de conhecer os projetos de vida de jovens adultos que convivem com o HIV/ aids a partir da transmissão vertical, com relação a: estudo, trabalho e constituição familiar. Outro objetivo foi o de conhecer sua vivência no que diz respeito à assistência recebida.

\section{Método}

Foi adotada a metodologia qualitativa de pesquisa, com a técnica da entrevista semiestruturada (Nogueira-Martins e Bógus, 2004), acompanhada de um questionário sociodemográfico. As questões norteadoras da entrevista foram: "Conte-me como é o seu dia a dia"; "Fale-me sobre seus projetos de vida”; "Quais são, a seu ver, as principais dificuldades presentes atualmente na sua vida?"; "Como tem sido sua vivência de atendimento com relação a seu estado de saúde?".

A partir da lista de pacientes com perfil pertinente aos objetivos da pesquisa (pessoas soropositivas por transmissão vertical e que tivessem idade entre 18 e 24 anos), disponibilizada por infectologistas do hospital, o acesso aos pacientes foi facilitado e, assim, os jovens que compareciam aos exames e consultas agendadas eram convidados a participar espontaneamente da pesquisa. Todos os pacientes foram entrevistados no ambulatório do hospital. Na data e horário das consultas e exames, cada jovem foi informado sobre os objetivos do trabalho e recebeu esclarecimentos sobre a sua condição de voluntário e sobre a isenção de qualquer custo ou remuneração, bem como sobre o caráter confidencial e a liberdade de desistência de sua participação.

O paciente que concordava em ser entrevistado era informado sobre a gravação e transcrição de sua entrevista, assim como sobre seu acesso ao material, sendo garantida a privacidade e o sigilo. Foi entregue o Termo de Consentimento Livre e Esclarecido, que consiste na anuência do sujeito, autorizando sua participação voluntária na pesquisa. 0 referido Termo foi apresentado em duas vias, que foram assinadas pelo entrevistado e pela pesquisadora, ficando uma cópia para cada um. Antes das entrevistas, foi entregue o questionário autoaplicado para identificação do perfil sociodemográfico ocupacional dos pacientes participantes da pesquisa. Houve, por parte da entrevistadora, a preocupação de manter uma postura ética com relação aos entrevistados, não ultrapassando os limites por eles estabelecidos (Silva e col., 2012); portanto, mesmo quando os desejos, curiosidades e expectativas da pesquisadora não eram contemplados em sua totalidade, a privacidade do jovem não era desrespeitada.

O material obtido nas entrevistas foi analisado segundo os princípios da análise temática (Nogueira-Martins e Bógus, 2004), por meio da qual os discursos são agrupados em temas afins.

\section{Resultados e Discussão}

Foram realizadas 18 entrevistas, que duraram, em média, 45 minutos cada, tendo sido descartadas 02 delas, pois uma era referente à transmissão horizontal e, em outra, não houve possibilidade de transcrição da fala do entrevistado.

A tabela a seguir apresenta o perfil dos jovens que tiveram suas entrevistas válidas.

Os jovens entrevistados apresentavam condição clínica controlada e estável, sem histórico de internação recente e a frequência ao ambulatório dava-se por acompanhamento de rotina para monitoramento de carga viral, $\mathrm{CD}_{4}$ e administração medicamentosa.

Da análise temática realizada com o material das entrevistas, emergiram seis categorias: estudo e escolaridade; trabalho e emprego; sexualidade e constituição familiar; vivência de preconceito; adesão ao tratamento; acolhimento.

\section{Estudo e escolaridade}

Por meio da educação, a pessoa pode alcançar a tomada de consciência de si e de sua realidade histórica e também fortalecer suas redes sociais (Freire, 1987; Seidl, 2001), conforme mostram os discursos de dois dos entrevistados:

Ninguém pode ficar sem estudo... é a base. É um conhecimento que ninguém te tira... Por que é algo que te faz crescer. É algo que você pode usarpara conquistar muitos meios de comunicação, emprego. Estudo ninguém nunca vai te tirar... (Entrevista o6)

Então épor isso que quando eu chego na faculdade, eu pareço outra pessoa... eu sou até mais alegre, converso mais com as pessoas... (Entrevista 13) 
Tabela - Dados sociodemográficos dos entrevistados, por variável ( $N$ : 16), em um ambulatório de Infectologia em São Paulo, fevereiro a dezembro de 2009

\begin{tabular}{|c|c|c|c|}
\hline & Variável & $\mathrm{N}$ & (\%) \\
\hline \multirow[t]{2}{*}{ Sexo } & Masculino & 05 & 31,2 \\
\hline & Feminino & "I & 68,8 \\
\hline \multirow[t]{5}{*}{ Idade } & 18 & 04 & 25,0 \\
\hline & 19 & 04 & 25,0 \\
\hline & 20 & 04 & 25,0 \\
\hline & 21 & 03 & 18,7 \\
\hline & 22 & Ol & 6,3 \\
\hline \multirow[t]{2}{*}{ Estado civil } & Solteiro & 14 & 87,5 \\
\hline & União estável & 02 & 12,5 \\
\hline Local nascimento & São Paulo & 16 & 100,0 \\
\hline \multirow[t]{3}{*}{ Cor } & Branca & 09 & 56,3 \\
\hline & Negra & 04 & 25,0 \\
\hline & Parda & 03 & 18,7 \\
\hline \multirow[t]{4}{*}{ Escolaridade } & Ensino fundamental incompleto & ol & 6,3 \\
\hline & Ensino médio completo & 08 & 50,0 \\
\hline & Ensino médio incompleto & 05 & 31,2 \\
\hline & Ensino superior (em curso) & 02 & 12,5 \\
\hline \multirow[t]{4}{*}{ Religião } & Católica & 06 & 37,5 \\
\hline & Evangélica & 06 & 37,5 \\
\hline & Espírita & OI & 6,3 \\
\hline & Não tem & 03 & 18,7 \\
\hline \multirow[t]{5}{*}{ Renda familiar } & De I a 2 salários mínimos & 03 & 18,7 \\
\hline & De 2 a 3 salários mínimos & 03 & 18,7 \\
\hline & De 3 a 5 salários mínimos & 07 & 43,8 \\
\hline & De 5 a 10 salários mínimos & 02 & 12,5 \\
\hline & De 10 a 20 salários mínimos & ol & 6,3 \\
\hline \multirow[t]{3}{*}{ Filhos } & Nenhum & 14 & 87,4 \\
\hline & Um & ol & 6,3 \\
\hline & Dois & Ol & 6,3 \\
\hline \multirow[t]{2}{*}{ Trabalho remunerado } & Não & 10 & 62,5 \\
\hline & Sim (de I a 2 salários mínimos) & 06 & 37,5 \\
\hline \multirow[t]{5}{*}{ Com quem vive } & Familiares (avós e/ou tios biológicos) & 08 & 50,0 \\
\hline & Pais adotivos & 03 & 18,7 \\
\hline & Cônjuge e filhos & 02 & 12,5 \\
\hline & Com amigos & 02 & 12,5 \\
\hline & Sozinho & ol & 6,3 \\
\hline
\end{tabular}


Alguns entrevistados relacionaram diretamente sua vontade de estudar à necessidade de melhor qualificação profissional e melhor remuneração:

Eu faço Administração... o que eu quero fazer é montar uma firma para mim... ser um empresário... pretendo crescer no que eu estou fazendo... seguir nisso que eu estou estudando e... sei lá... me jogar na vida... tentar... (Entrevista 13)

... o mercado de trabalho cobra os estudos... também porque aí passa a ganhar um pouco mais... não arranja um serviço tão pesado... (Entrevista 14)

Entretanto, nem todos os entrevistados conseguiram levar adiante seus estudos. Em congruência ao apontado pelo Manual de Rotinas para assistência a adolescentes vivendo com HIV/aids (Brasil, 2006), alguns relatos de abandono escolar foram motivados pela falta de incentivo da família e por gravidez precoce.

Do estudo, eu desisti... minha tia fala que no estudo eu sou burra... ela falou que tem muitas coisas em que eu sou esperta, dos outros lados, sem ser escola... Eu já fiquei em reforço, professor já ficou na minha orelha... mas não adianta... (Entrevista o1)

Eu tive que parar na segunda série do segundo grau... [Pretendo retomar os estudos] no ano que vem, porque eles [filhos gêmeos de quatro meses] vão estar mais maiorzinhos e já vai dar para pôr na creche. (Entrevista 04 )

Dificuldades financeiras e incompatibilidade com o horário de trabalho também foram referidas como motivo de interrupção do estudo.

É. Eu comecei, só que é muito caro você pagar faculdade de Direito... É caro... aí eu tive que trancar... (Entrevista o6)

Eu quero arrumar um serviço que dê com o meu horário... Que dê o meu serviço e o meu horário de estudo... porque eu nunca tive um serviço que tivesse esse horário... por isso que eu parei no primeiro [ano do ensino médio]. (Entrevista 14)

\section{Trabalho e emprego}

O trabalho, além de caminho para a subsistência e autonomia, é também capaz de sedimentar a identidade que vem sendo almejada pelos jovens desde a adolescência (Ciampa, 1999). O fato de ser trabalhador, para alguns jovens portadores de HIV, demonstra possibilidade de afirmar sua capacidade de realizações e conquistas:

O importante é que eu vou estar trabalhando e um dia eu - se eu tiver minha família, meus filhos - vou poder falar pra eles: 'Ó, esse aqui foi com o dinheiro da mãe... Sua mãe trabalhou muito pra conseguir isso aqui!' $\varepsilon$ o que eu quero. (Entrevista 03)

Projeto de vida pra mim?... É trabalhar... para ser alguém na vida. (Entrevista 10)

Em muitos casos, o trabalho é o meio pelo qual o jovem passa a adquirir maior autonomia, ascensão social e também é fonte de sustento e manutenção da família (Sarriera e col., 2004). Alguns jovens entrevistados demonstraram que sua perspectiva quanto ao trabalho está diretamente relacionada a estas necessidades:

... Eu vou estudar e trabalhar e vou morar sozinha e não quero ser dependente de ninguém, de homem, principalmente, eu quero homem bem longe de mim... Eu tenho 21, até os 25 eu estou procurando sair de lá [da casa dos tios]. (Entrevista 12)

Em alguns casos, o benefício recebido por meio da LOAS vem a ser um fator de exclusão no que diz respeito à inserção formal ao mercado de trabalho. Alguns entrevistados optariam em abrir mão do benefício em função de uma atividade remunerada, com carteira de trabalho registrada:

Tem um problema: se eu for trabalhar [nesse lugar], eu já sei que tem que ser registrada e eles sabem que eu falei que eu não posso ser, porque eu recebo o INSS. Se eu for registrada, vão suspender minha aposentadoria. Aívai ficar pior, porque eu vou ficar com pouco dinheiro. (Entrevista o1)

Alguns jovens referiram dificuldades no que diz respeito às faltas ao trabalho por motivo de tratamento.

Quando eu estava trabalhando... Então eu falava: 'Ó, eu tenho médico e amanhã eu não venho!'. Porque eu venho [ao hospital] uma vez a cada dois meses. Era difícil. (Entrevista 02)

Outros manifestaram muito receio quanto a como se comportar em um possível emprego, no que diz respeito à sua doença. 
... então eu fico meio insegura de arranjar um emprego e não me adaptar... ou que aconteça alguma coisa comigo e eu tenha que contar o meu problema... ou se eu passar mal e... 'Ai, por que você passou mal? Você tem que irno médico.' Então você tem que levar $o$ atestado e o atestado vem o nome do hospital e você fica exposta... (Entrevista 11)

\section{Sexualidade e constituição familiar}

A condição sorológica tem causado receio quanto à possível rejeição do(a) parceiro(a), motivando o jovem, conforme alguns relatos, a retardar a revelação, até que se sinta em uma relação minimamente estável:

O que eu acho mais difícil pra mim? Acho que é eu ter uma relação com uma pessoa... é de expor o problema que eu tenho. Acho que eu tenho medo de contar e a pessoa rejeitar. (Entrevista 10)

$\varepsilon u$ fico pensando em contar pra ele e ele, de repente, sumir... (Entrevista 11)

Alguns entrevistados demonstraram desejo de constituir família unindo-se a um(a) parceiro(a), realizando o desejo da maternidade/paternidade, não considerando a condição sorológica como impeditivo para a concretização desse objetivo (Ayres e col., 2004; Polejack e Costa, 2002):

... Deus é união e Deus não fez a gente para ficar sozinho. E eu comecei a gostar da ideia de ser mãe, de me casar na igreja, vestida de noiva e tal... (Entrevista 12)

... Penso em casar, penso em ter filhos. Eu já namoro há dois anos, então a gente conversa muito sobre isso... Eu quero constituir uma família, eu quero ter os meus filhos! (Entrevista 16)

Outros referem intenção de terem filhos sem formar família nos moldes tradicionais:

... Eu quero ter uma produção independente... eu não sei se é por que eu vejo alguns casais muito problemáticos... Eu quero um menino, se na primeira tentativa não der um menino e vier uma menina eu tenho o segundo... Meu sonho é ter um menino. (Entrevista 15)

Outros, ainda, não tencionam ter filhos, influenciados pela vivência e sofrimento causados pela portabilidade do HIV.
... Não tendo filhos, [posso] cuidar só de mim... colocar um nenezinho para sofrer... ninguém merece!" (Entrevista o6)

\section{Vivência de preconceito}

Tal como no estudo de Meneghel e colaboradores (2008), foram referidas pelos entrevistados várias atitudes preconceituosas em diversos contextos: família, trabalho, escola e outros.

Alguns jovens relataram experiências em que foram vítimas de preconceito no contexto intrafamiliar:

A cunhada da minha tia provavelmente tem muito preconceito... quantas crianças ela já tirou de perto de mim... Ela [diz]: 'Não, não! Não chega perto não! Pelo amor de Deus!'... (Entrevista o1)

A mãe do meu marido tem muito preconceito... Ela liga em casa me chamando de aidética; aí eu desligo na cara dela. (Entrevista 04 )

O trabalho também foi citado por vários entrevistados, como um contexto em que o preconceito foi por eles vivenciado, sendo uma das preocupações a questão do atestado com o nome do hospital, para justificar as faltas por motivo de consulta médica.

Foi até melhor eu falar. Ele [o chefe direto] me acolheu de braços abertos e só falou que não era para comentar com ninguém de lá de dentro, por causa do preconceito. (Entrevista o8)

Então, tem isso. Eu fico preocupada: 'Nossa!! Meu Deus!!! E se eles veem isso?!' Da última vez que eu vim [no hospital], eu levei o atestado e aí estava lá [o timbre do hospital], só que eu não sei se a menina reparou, não sei. Se eu tiver que dar o atestado de novo, eu vou ver se eu arrumo uma etiqueta para colar em cima..." (Entrevista 12)

Na escola, também foi sentido o preconceito, especialmente quando os entrevistados eram mais jovens, época em que era importante a comunicação do diagnóstico para a escola.

Na escola, quando eu era pequena, a gente sofria muito, eu e minhas irmãs... então como eu era muito pequenininha e muito magrinha, minhas irmãs brigavam muito por minha causa. $\varepsilon$ rolava preconceito de não sentar perto e coisas assim. (Entrevista 12) 
A partir da adolescência, a tendência é a de não revelar o diagnóstico:

Na escola, eu não falo porque não vejo necessidade. (Entrevista o8)

Os portadores de HIV têm demonstrado, mais do que há algumas décadas, maior capacidade de enfrentamento quando expostos a expressões de discriminação (Garcia e Koyama, 2008).

Ah! Eu fico normal, porque se a gente abaixa a cabeça é pior... tem que erguer a cabeça... e se eu não erguer minha cabeça e abaixar para eles los que têm preconceito], é pior... aí eles sobem em cima de mim...” (Entrevista 04)

\section{Adesão ao tratamento}

Por meio da medida instaurada a partir de 1996, que garante a distribuição gratuita de medicamentos para tratamento do HIV em todo o País (Greco, 2008), os jovens portadores do vírus também são contemplados por essa ação. Porém, na tentativa de demonstrar insatisfação e/ou autonomia, podem se tornar não aderentes ao tratamento (Tavares, 2003). Alguns jovens entrevistados revelaram sua relação com o tratamento e, em alguns casos, suas dificuldades em manter constante a administração da medicação:

Ah! Já parei de tomar [a medicação], porque era líquido e era horrível o remédio... E eu já joguei fora o comprimido... na pia. Já fui uma pestinha... mas agora, estou me cuidando. (Entrevista 07)

Alguns entrevistados revelaram sua relação com o tratamento e os recursos que utilizam para manterse tomando a medicação:

... Então, eu tomo esse remédio... eu tomo por tomar, porque é legal, vamos dizer assim... Já é igual a escovar os dentes, tomar banho, arrumar a cama, é a mesma coisa. (Entrevista og)

$\varepsilon$ a mesma coisa que uma mulher que está tomando um anticoncepcional. $\varepsilon$ a mesma coisa. Tem que pensar dessa forma:é para evitar que fique doente. A mulher não toma [anticoncepcional] para não ficar grávida? (Entrevista o6)

\section{Acolhimento}

Os órfãos da aids, constituídos por grande parte dos jovens que convivem com o HIV/aids por transmissão vertical, vivem uma situação muito diferente quando comparada à de outros órfãos, pois o preconceito, muitas vezes, faz com que sejam rejeitados por componentes da família mais ampla, como tios, avós e outros (Santos, 2006).

Nesse contexto, adquire grande significado o fato de alguns deles terem sido criados por familiares:

Eles que me criaram... minha avó que me criou, me trouxe durante anos ao hospital, minha tia também... É porque mãe é aquela que cria... Então eu não sinto falta da minha mãe [que é falecida]... (Entrevista 06)

Os que foram adotados por pessoas não pertencentes ao círculo familiar também reconhecem a importância de terem recebido o afeto da nova família.

... Então, eu acho que o que me faz viver e acreditar que eu sou feliz é o amor da minha família para comigo. Não existe coisa melhor que isso... problemas todo mundo tem. Mas o amor deles me faz enfrentar qualquer problema. (Entrevista o9)

Cuidados quanto à revelação diagnóstica, quando aliados ao suporte familiar e profissional, são elementos importantes para que o jovem portador de HIV possa adquirir suporte emocional para lidar com a doença e suas particularidades (Marques e col., 2006).

No que diz respeito aos serviços de saúde, o acolhimento é uma diretriz da Política Nacional de Humanização (PNH), que não tem local nem hora certa para acontecer, nem um profissional específico para fazê-lo: deve permear todo o contexto assistencial. 0 acolhimento é uma postura ética que implica na escuta do usuário em suas queixas, no reconhecimento do seu protagonismo no processo de saúde e adoecimento, e na responsabilização pelo vínculo. Acolher é um compromisso de resposta às necessidades dos cidadãos que procuram os serviços de saúde, constituindo fator relevante no resgate e fortalecimento da autoestima das pessoas atendidas nos serviços de saúde, e como parte integrante dos fatores relacionados à melhoria da qualidade de vida, da inclusão social e da adesão ao tratamento (Brasil, 2003).

$\mathrm{O}$ acolhimento por parte da equipe de saúde teve e tem especial importância na vida dos entrevista- 
dos. O vínculo estabelecido com os profissionais é importante como referência na vida desses jovens, o que os ajuda a enfrentar situações difíceis:

Eles [os profissionais que me atendem] têm muita paciência comigo, porque se fossem outros, já tinham largado meu caso. Eu acho bom eles se preocuparem comigo e tentarem me ajudar, vendo a maneira certa de estar me ajudando, para eu voltar a tomar os medicamentos direito... (Entrevista 03)

Os jovens entrevistados demonstraram receber um atendimento sensível a essa fase de mudanças, uma vez que são atendidos por uma equipe compartilhada entre pediatras e médicos de adultos, os quais promovem uma transição do atendimento clínico gradativa, atentos ao desejo e maturidade de cada jovem paciente, colaborando para a sedimentação de um vínculo satisfatório, que gera confiança e melhor adesão ao tratamento.

Os médicos daqui são muito bons para mim... Eles atendem muito bem. A médica me atende desde os dois anos... todo mundo quer que eu mude para outra... Mas eu não vou não... As mulheres ficam até falando: 'Ainda você passa com ela? Mas só que é de criança.' Mas desde pequenininha ela cuida de mim... (Entrevista o4)

\section{Considerações Finais}

Os jovens entrevistados que, vale lembrar, fazem parte do grupo daqueles que, há duas décadas aproximadamente, por conta das então condições medicamentosas e terapêuticas ligadas à aids, eram considerados como condenados à morte, revelam que seus projetos de vida existem e estão em constante construção/reconstrução.

0 ambiente escolar foi referido como meio para a inserção social, assim como para a conquista da autonomia, colaborando para a sedimentação de sua identidade. A estratégia de manter oculta sua condição sorológica foi escolhida, na maioria dos casos, no sentido de evitar preconceito e discriminação.

O trabalho foi apresentado como principal fonte de subsistência e perpetuação da autonomia. Foi referido também como caminho para a obtenção de uma identidade produtiva, contribuindo para afastar o jovem da condição de doente e incapaz.
Quanto à conjugalidade, os projetos são variados: união de casais concretizada de maneira informal; desejo de permanecerem sozinhos (tendo filhos ou não); intenção de se unir a um(a) companheiro(a) por meio dos trâmites formais. A maior preocupação dos jovens nas relações afetivo-sexuais é com a possível contaminação do(a) parceiro(a). A realização do desejo de ter filhos foi marcadamente influenciada pela portabilidade do HIV, fazendo com que tivessem dúvidas ou desistissem de tal projeto.

O estigma foi importante fenômeno de interferência no âmbito social; com matizes variados, os jovens demonstraram estar encontrando estratégias para a inserção e permanência nos diversos grupos sociais.

$\mathrm{O}$ acolhimento vivenciado por muitos desses jovens, incluindo os cuidados dispensados pelas equipes do hospital, foi elemento de grande importância para a minimização do sofrimento dos sujeitos e para a elaboração e concretização de muitos aspectos de seus projetos de vida. A sensibilidade das equipes de saúde foi ressaltada, no sentido de estas apresentarem um formato de transição em que pediatras e médicos de adolescentes e de adultos promovem um tipo de transição em que são flexibilizados os atendimentos de acordo com as necessidades do jovem, ao invés do estabelecimento de um limite rígido, em que haveria mudanças obrigatórias de profissionais quando o paciente atingisse determinada idade (modelo esse pelo qual o pediatra, por exemplo, só atenderia crianças).

Há que se fomentar pesquisas que aprofundem o estudo em cada um dos itens que compõem o tripé - trabalho, estudo e constituição familiar -, de modo a entender outros aspectos específicos dessas questões.

\section{Referências}

AMAZONAS, M. C. L. A.; BRAGA, M. G. R. Reflexões acerca das novas formas de parentalidade e suas possíveis vicissitudes culturais e subjetivas. Ágora, Rio de Janeiro, v. 9, n. 2, p. 177-191, 2006. ARENDT, H. A condição humana. São Paulo: Universitária, 1987. 
AYRES, J. R. C. M. et al. Adolescentes e jovens vivendo com HIV/aids: cuidado e promoção da saúde no cotidiano da equipe multiprofissional. São Paulo: Enhancing Care Iniciative, 2004.

BOUTINET, J. P. Antropologia do projeto. Lisboa: Instituto Piaget, 1990.

BRASIL. Ministério da Saúde. Política Nacional de Humanização (PNH): humanização da atenção e da gestão em saúde no Sistema Único de Saúde SUS. Brasília, DF, 2003.

BRASIL. Ministério da Saúde. Secretaria de Vigilância em Saúde. Programa Nacional de DST e Aids. Manual de rotinas para assistência de adolescentes vivendo com HIV/aids. Brasília, DF, 2006.

CATÃO, M. F. Excluídos sociais em espaço de reclusão: representações sociais na construção do projeto de vida. 2001. Tese (Doutorado em Psicologia) - Instituto de Psicologia, Universidade de São Paulo, São Paulo.

CIAMPA, A. C. Identidade. In: CODO, W.; LANE, S. T. M. Psicologia social: o homem em movimento. São Paulo: Brasiliense; 1999. p. 10-64.

COHEN, J. et al. School-related issues among HIVinfected children. Pediatrics, Elk Grove Village, Illinois, v. 100, p. 8-11, 1997.

DAVIS, C; SILVA, M. A. S. S.; ESPÓSITO, Y. Papel e valor das interações sociais em sala de aula. Cadernos de Saúde Pública, Rio de Janeiro, v. 71, p. 49-54, 1989.

FREIRE, P. Pedagogia do oprimido. Rio de Janeiro: Paz e Terra, 1987.

GARCIA, S.; KOYAMA, M. A. H. Estigma, discriminação e HIV/Aids no contexto brasileiro, 1998 e 2005. Revista de Saúde Pública, São Paulo, v. 42, n. 1, p. 72-83, 2008.

GRECO, D. B. A epidemia da aids: impacto social, científico, econômico e perspectivas. Estudos Avançados, São Paulo, v. 22, n. 64, p. 73-94, 2008.
GRIMGERG, M. Sexualidad, experiencias corporales y género: un studio etnografico entre personas viviendo com VIH em el área metropolitana de Buenos Aires, Argentina. Cadernos de Saúde Pública, Rio de Janeiro, v. 25, n. 1, p. 133-141, 2009.

GUIMARÃES M. S.; RAXACH J. C. A questão da adesão: os desafios impostos pela aids no Brasil e as respostas do Governo, de pessoas e da sociedade. Revista Ciências Sociais e Humanas, Piracicaba, v. 32, n. 13, p. 69-90, 2002.

GUTIERREZ, D. M. D.; MINAYO, M. C. S. Família, redes sociais e saúde: o imbricamento necessário. Fazendo gênero - corpo, violência e poder. Florianópolis, v. 8, p. 1-8, 2008.

MARQUES, H. H. S. et al. A revelação do diagnóstico na perspectiva dos adolescentes vivendo com HIV/aids e seus pais e cuidadores. Cadernos de Saúde Pública, Rio de Janeiro, v. 22, n. 3, p. 619-629, 2006.

MENEGHEL, S. N. et al. Histórias de dor e de vida: oficinas de contadores de histórias. Saúde e Sociedade, São Paulo, v. 17, n. 2, p. 220-228, 2008.

NASCIMENTO, I. P. As representações sociais do projeto de vida dos adolescentes: um estudo psicossocial. 2002. Tese (Doutorado em Educação) - Pontifícia Universidade Católica, São Paulo.

NOGUEIRA-MARTINS, M. C. F.; BÓGUS, C. M. Considerações sobre a metodologia qualitativa como recurso para o estudo das ações de humanização em saúde. Saúde e Sociedade, São Paulo, v. 13, n. 3, p. 44-57, 2004.

OIT - Organização Internacional do Trabalho. HIV/ aids no mundo do trabalho: as ações e a legislação brasileira. Brasília: OIT, 2002.

POLEJACK, L.; COSTA, L. F. Aids e conjugalidade: o desafio de com (viver). Revista de Ciências Sociais e Humanas, Piracicaba, v. 13, n. 1, p. 131-139, 2002.

REIS, J. R. T. Família, emoção e ideologia. In: CODO, W.; LANE, S. T. M. Psicologia social: o homem em movimento. São Paulo: Brasiliense, 2001. p. 99-123. 
SANTOS, A. S. A. Notas sobre a solidariedade e o fenômeno da orfandade na sociedade Akan-Agni Morofoé da Costa do Marfim (África Do Oeste). Saúde e Sociedade, São Paulo, v. 15, n. 3, p. 40-56, 2006.

SARRIERA, J. C. et al. Os (des)caminhos dos jovens na sua passagem da escola ao trabalho In: . Psicologia comunitária: estudos atuais.

São Paulo: Ed. Salina, 2004. p. 43-105.

SAWAIA, B. Exclusão ou inclusão perversa? In: SAWAIA, B. As artimanhas da exclusão: análise psicossocial e ética da desigualdade social.

Petrópolis: Vozes, 1999. p. 7-13.

SEIDL, E. M. F. Pessoas vivendo com HIV/aids: configurando relações entre enfrentamento, suporte social e qualidade de vida. 2001. Tese (Doutorado em Psicologia) - Universidade de Brasília, Brasília.
SILVA, C. R. C.; MENDES, R.; NAKAMURA, E. A dimensão da ética na pesquisa em saúde com ênfase na abordagem qualitativa. Saúde e Sociedade, São Paulo, v. 21, n. 1, p. 32-41, 2012.

TAVARES, M. C. T. A experiência de adolescer com aids. 2003. Dissertação (Mestrado em Enfermagem) - Universidade Federal de Minas Gerais, Belo Horizonte.

VERNAZZA, P. L. et al. HIV-discordant couples and parenthood: how are we dealing the risk of transmission? AIDS, London, v. 2o, n. 4, p. 635-36, 2006.

VYGOTSKY, L. S. O desenvolvimento dos processos psicológicos superiores. In: VYGOTSKY, L. S. A formação social da mente. São Paulo: Martins Fontes, 2007. p. 26-54. 